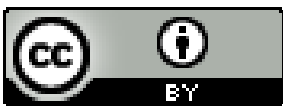

\title{
“O MUNDO NO BLACK POWER DE TAYÓ": IDENTIDADE, EDUCAÇÃO E MULTICULTURALIDADE
}

\author{
Mariana de Souza Alves ${ }^{1}$ \\ Érica Montenegro Mélo ${ }^{2}$ \\ Hilda Pimentel Carvalho de Souza ${ }^{3}$
}

Resumo: Trata de uma análise da obra literária "O mundo no black power de Tayó", história de uma menina que projeta em seu penteado black power, o reconhecimento e valorização da identidade da população negra e por meio dele expressa sua autonomia, beleza e felicidade. Para isso, a pesquisa utiliza alguns conceitos socioantropológicos, tais como, cultura, negritude e pós-colonialismo, além de uma perspectiva educacional e literária acerca de como esses pilares são trabalhados nessas duas instâncias. Conclui que a literatura infantil é um recurso importante para o desenvolvimento de práticas e discussões pedagógicas que promovam a reflexão sobre a multiculturalidade e o consequente combate à discriminação por meio da valorização da ancestralidade, história e cultura de cada povo fortalecendo a identidade da criança para que ela possa sentir-se como Tayó, com sua personalidade fortalecida e pronta para enfrentar com leveza e atitude as mais diversas manifestações de indiferença e atos discriminatórios.

Palavras-chaves: Literatura infantojuvenil. Identidade. Cultura. Escola. Multiculturalidade. Negritude.

\section{"THE WORLD IN THE BLACK POWER OF TAYÓ": IDENTITY, EDUCATION AND MULTICULTURALITY}

Abstract: It deals with an analysis of the literary work "The world in black power of Tayó", a story of a girl who projects in her black power hairstyle, the recognition and

\footnotetext{
${ }^{1}$ Doutoranda em Ciência da Informação pela Universidade Federal de Pernambuco (UFPE) - 2019. Especialista em Literatura Infantojuvenil pela Faculdade Frassinetti do Recife (FAFIRE-PE) - 2018. Mestre em Ciência da Informação, UFPE - 2017. Bibliotecária da Universidade Federal de Pernambuco. Mediadora de leitura e contadora de histórias. E-mail: mdsa24@gmail.com
${ }^{2}$ Mestre em Ciências da Linguagem pela Universidade Católica de Pernambuco (UNICAP). Especialista em Literatura Infantojuvenil pela FAFIRE-PE. Psicopedagoga. Pedagoga. Mediadora de leitura e contadora de histórias. Cordelista. Escritora com cinco livros publicados. Brinquedista. Membro da Equipe Técnico-pedagógica da Rede Municipal do Jaboatão dos Guararapes. E-mail: emontemelo@gmail.com

\footnotetext{
${ }^{3}$ Especialista em literatura infantojuvenil. Assistente Social. Diretora Editorial da Mundo Educacional. Diretora Pedagógica da Mídia Express. E-mail: hildapcsouza@gmail.com
}

Revista da ABPN・v. 12, n. $31 \cdot \operatorname{dez} 2019$ - fev 2020, p. 470-491 
valorization of the identity of the black population and through it expresses its autonomy, beauty and happiness. For this, the research uses some socio-anthropological concepts, such as, culture, negritude and postcolonialism, besides an educational and literary perspective on how these pillars are worked in these two instances. It concludes that children's literature is an important resource for the development of practices and pedagogical discussions that promote reflection on multiculturalism and the consequent fight against discrimination through the valorization of the ancestry, history and culture of each folk, strengthening the identity of the child so that she can feel like Tayó, with her personality strengthened and ready to face with lightness and attitude the most diverse manifestations of indifference and discriminatory acts.

Keywords: Children's Literature. Identity. Culture. School. Multiculturality. Blackness.

\section{"EL MUNDO EN EL BLACK POWER DE TAYÓ": IDENTIDAD, EDUCACIÓN Y MULTICULTURALIDAD}

Resumen: Se trata de un análisis de la obra literaria "El mundo en el black power de Tayó", historia de una niña que proyecta en su peinado black power, el reconocimiento y valoración de la identidad de la población negra y por medio de él expresa su autonomía, belleza y felicidad. Para ello, la investigación utiliza algunos conceptos socioantropológicos, tales como, cultura, negritud y post-colonialismo, además de una perspectiva educativa y literaria acerca de cómo esos pilares son trabajados en esas dos instancias. Concluye que la literatura infantil es un recurso importante para el desarrollo de prácticas y discusiones pedagógicas que promuevan la reflexión sobre la multiculturalidad y el consecuente combate a la discriminación por medio de la valorización de la ancestralidad, historia y cultura de cada pueblo fortaleciendo la identidad del niño para que ella puede sentirse como Tayó, con su personalidad fortalecida y lista para enfrentar con ligereza y actitud las más diversas manifestaciones de indiferencia y actos discriminatorios.

Palabras-clave: Literatura infantojuvenil. Identidad. Cultura. Escuela. Multiculturalidad. Negritud.

\section{"LE MONDE À LA BLACK POWER DE TAYÓ": IDENTITÉ, ÉDUCATION ET MULTICULTURALITÉ}

Resumé: Il s'agit d'une analyse de l'œuvre littéraire "Le monde en black power de Tayó", l'histoire d'une jeune fille qui projette dans sa coiffure en black power, la reconnaissance et la valorisation de l'identité de la population noire et à travers elle exprime son autonomie, sa beauté et son bonheur. Pour cela, la recherche utilise des concepts socio-anthropologiques, tels que culture, négritude et postcolonialisme, en plus d'une perspective éducative et littéraire sur la manière dont ces piliers sont travaillés dans ces deux cas. Il conclut que la littérature pour enfants est une ressource importante pour le développement de pratiques et de discussions pédagogiques favorisant la réflexion sur le multiculturalisme et la lutte contre la discrimination qui en découle, grâce à la valorisation de l'ascendance, de l'histoire et de la culture de chaque peuple, renforçant ainsi l'identité de l'enfant. elle peut se sentir comme Tayó, avec sa personnalité renforcée et prête à affronter avec légèreté et attitude les manifestations les plus diverses d'indifférence et d'actes discriminatoires. 
Most-clés: Littérature pour enfants. Identité. La culture. L'école. Multiculturalité. Négritude.

\section{INTRODUÇÃO}

"Seu rosto parece uma moldura de valor, que destaca belezas infinitas" (OLIVEIRA, 2013, p.8).

Este trabalho trata de uma breve análise da obra literária "O mundo no black power de Tayó" (OLIVEIRA, 2013), no que diz respeito à sua composição literária e temática, sobretudo no que é referente à valorização da identidade negra. Considerada uma obra infantojuvenil, o livro escrito por Kiusam de Oliveira traz a história de uma menina que projeta em seu penteado black power o reconhecimento e a valorização da identidade da população negra e por meio dele expressa seus sentimentos, sua beleza e felicidade.

Para compreender e analisar tal obra, iniciamos a discussão com a descrição de alguns conceitos socioantropológicos que se tornaram a base do nosso estudo, tais como cultura, negritude e pós-colonialismo. Nos utilizamos também de uma abordagem que parte de uma perspectiva educacional e literária acerca de como esses pilares são trabalhados nessas duas instâncias. Escolhemos a análise socioantropológica, visto que são dois ramos da ciência que, juntos, buscam entender e explicar as relações dos sujeitos na sociedade no que tange as suas semelhanças e diferenças em suas diferentes culturas e contextos sócio-históricos.

Neste sentido, ao se tratar de diferenças e de cultura entramos no domínio da diversidade cultural e todas as suas implicações histórico-sociais. Por isso, como a obra por nós analisada traz à tona os temas da identidade, das culturas africanas e consequentemente do racismo é relevante destacar algumas concepções que o permeiam, bem como perceber a importância dessa obra para o tratamento das temáticas que envolvem os mais diversos tipos de discriminação.

\section{IDENTIDADE: MULTICULTURALIDADE E EDUCAÇÃO}

"Seus olhos são negros, tão negros como as mais escuras e belas noites que do alto miram com ternura qualquer ser vivo" (OLIVEIRA, 2013, p.11).

Revista da ABPN • v. 12, n. $31 \cdot \operatorname{dez} 2019$ - fev 2020, p. 470-491 
A diversidade cultural é um elemento inegável e vital para o desenvolvimento das ações humanas. No entanto, a história da humanidade nos tem revelado que a humanidade, por diversos motivos políticos e econômicos, não admite ou tem dificuldade em reconhecer o valor da diferença, pois se utilizou de um tipo de cultura para causar opressão e exploração em outras, renegando-as a um plano inferior.

Nesse sentido, ao estudar as relações humanas nos deparamos com diversas formas de violência física e simbólica que originaram tipos de discriminações diversos contra alguns grupos culturais/étnicos, as quais persistem até os dias de hoje, numa tentativa de imposição cultural (homogeneização) principalmente por parte dos colonizadores. Moreira (1999, p. 84) discorre que as formas de vida e as culturas dos grupos privilegiados "são tidas como os únicos padrões aceitáveis, ao passo que as dos outros, as dos marginais, são vistas como uma ameaça à homogeneização cultural perseguida, o que faz com que sejam desvalorizadas, desrespeitadas e reprimidas”.

Tal movimento, denominado etnocentrismo, parte de uma conviç̧ão cujo princípio se baseia na ideia de que a cultura do outro é estranha e errada e a partir disso, discrimina a cultura desviante. Todavia, é preciso compreender que cada cultura tem uma lógica própria de organização, portanto, cada cultura se estrutura de um modo diferente. $\mathrm{O}$ desconhecimento e a rejeição disso causa o etnocentrismo, ou seja, a estranheza ao diferente e às vezes até mesmo a imposição de uma cultura sobre outra. Por isso, "a coerência de um hábito cultural somente pode ser analisada a partir do sistema a que pertence" (LARAIA, 2009, p. 87). Quer dizer, a visão de mundo que cada pessoa possui, condicionada por sua cultura é o que define como ela vai se colocar perante o outro e suas construções.

Desse modo, nada tem de errado ou ilógico conhecimentos e concepções de outros povos que divergem da nossa estrutura cultural. Um bom exemplo disso são as diversas explicações para os fenômenos da natureza que se estabelecem para cada povo. Embora haja comprovação científica acerca de como ocorre alguns fenômenos naturais, diversos povos possuem opiniões diferentes sobre esses mesmos eventos da natureza, seja por não terem meios e instrumentos específicos para captar essas realidades ou por não se permitirem fazê-lo. No entanto, não é por isso que tais conhecimentos vão ser desconsiderados. Essa ideia de captação da realidade pelas diversas óticas é, por exemplo, algo que muitas vezes não é trabalhado na família, tampouco na escola, onde 
se valoriza e se dissemina uma cultura etnocêntrica, na qual os (as) estudantes, desde a mais tenra idade, são convidados a pensar o mundo sob um único prisma.

Por isso, o julgamento não é ação mais adequada, até porque cada cultura vai trabalhar com o conceito que foi escolhido por ela, independente do que a ciência tenha comprovado, pois nem sempre todas as relações são entendidas da mesma maneira por todas as culturas (LARAIA, 2009). Moreira (1999, p. 84, baseado em McLaren, 1997, grifo nosso), reforça essa ideia, salientando que:

A cultura é, portanto, esfera de lutas, de diferenças, de relações de poder desiguais. Essas diferenças são sempre diferenças em relação a algo, não diferenças absolutas. São diferenças políticas, não apenas diferenças textuais, linguísticas, formais. São diferenças construídas com base em relações de poder estruturais e globais que não devem ser secundarizadas (MOREIRA, 1999, p. 84, baseado em MCLAREN, 1997, grifo nosso).

Mas o que podemos compreender como cultura, afinal? A cultura como um conceito plural (culturas), abarca uma infinidade de elementos pelos quais perpassa a vida cotidiana em sociedade, as quais se diferem em grande parte pela região e modo de vida específico de cada grupo. Dessa forma, não há apenas uma cultura, uma vez que cada sujeito é produtor e produto das construções dos que lhe circundam. As culturas incluem os costumes, a tradição popular, a tecnologia, normas e valores de cada povo. Incluem sobretudo, a ideia de mudança ou dinamicidade, de incompletude, aprendizado e produção, fatores preponderantes à vivência dos diversos grupos sociais (LARAIA, 2009).

Geertz (1989) defende que as categorias de cultura devem ser pensadas de maneira justapostas e interdisciplinares e não em partes separadas, ou seja, compreende que as culturas são incompletas, o que nos remete à ideia de multiculturalidade. Por isso, é necessário entender que a cultura é dinâmica, e que esse movimento é importante para que ela possa se refazer, considerando as construções de cada sujeito, a partir das novas demandas e ideias que vão surgindo nesse viver e conviver em sociedade.

Assim, todas as culturais são dinâmicas, em que pese algumas terem um ritmo de mudança menor do que outras, pois diferentemente de um formigueiro, por exemplo, as sociedades humanas possuem a capacidade de questionar os seus próprios hábitos e modificá-los. Nas sociedades mais isoladas o ritmo de mudança é menos acelerado do que as sociedades mais complexas, as quais são influenciadas por constantes inovações 
tecnológicas (LARAIA, 2009). Essas inovações interferem constantemente nas produções socioculturais, uma vez que, por exemplo, produzem um grande número de informações que circulam e se reconstituem constantemente.

Da mesma forma, García Canclini (2005) destaca a questão da interculturalidade como uma característica inerente do mundo globalizado; nas palavras de Moreira (1999, p. 85) "queiramos ou não, vivemos em um momento inescapavelmente multicultural". García Canclini continua dizendo que com a globalização houve uma transnacionalização material e simbólica, modificando a interação dos indivíduos com a sociedade e, portanto, reconfigurando a noção de sujeito (GARCÍA CANCLINI, 2005).

Assim, a crença de que os sujeitos são marcados por uma nacionalidade e etnia e que essa relação se estabelece unicamente com essas instâncias durante toda a vida não se sustenta mais, visto que atualmente as identidades dos sujeitos são formadas a partir de conexões interétnicas e internacionais. Hoje a formação do sujeito não se dá apenas pela cultura do país que nasceu, mas pela variedade de conteúdos simbólicos, do fluxo tecnológico e informacional e de modelos de condutas originados do mundo todo: “podemos cruzá-los e combiná-los” (GARCÍA CANCLINI, 2005, p. 201).

Contudo, é preciso dizer que embora haja esse reconhecimento por parte de alguns autores e embora seja inescapável a multi e interculturalidade entre os povos, a sociedade brasileira ainda enfrenta profundos desafios no que tange a inclusão social da população negra. Conforme Candau (2003, p.19), isso advém de raízes históricas, com relação intrínseca com processos de exclusão e, apesar de estarmos passando por profundas mudanças em algumas práticas sociais relacionadas à raça, ao gênero e à classe, a situação de "desvantagem em que os negros vivem mede-se pelas disparidades multidimensionais de que são vítimas e que se atualizam através do encobrimento e da dissimulação”. A partir de Santos (1997), Candau (2003) explica que:

[...] a escravidão marcou o território, marcou os espíritos e marca ainda hoje as relações sociais no país. A escravidão imposta ao povo negro, durante séculos, não só deixou incrustado o racismo na nossa história e constituiu um padrão de dominação que ainda não foi superado, como gravou no inconsciente coletivo a falsa convicção da inferioridade do negro, manifestada sob a forma de preconceito à brasileira, ou seja, um preconceito sutil, disfarçado, com vergonha de ser preconceito (CANDAU, 2003, p. 21, grifo da autora).

Assim, a autora revela a dificuldade do trabalho escolar com a temática do preconceito racial, pois a própria sociedade não admite nem reconhece o racismo. Nas 
Diretrizes Curriculares Nacionais para a Educação das Relações Étnico-Raciais e para o Ensino de História e Cultura Afro-Brasileira e Africana (BRASIL, 2004, p. 19), a escola é colocada como espaço onde se "deve orientar para o rompimento com imagens negativas forjadas por diferentes meios de comunicação, contra negros e os povos indígenas". Esse documento é de extrema importância para a construção de práticas sociais que levem em consideração o rompimento dos paradigmas de beleza, riqueza cultural e outros aspectos numa perspectiva etnocêntrica, que cotidianamente fortalecem o racismo em suas mais diversas manifestações.

Embora exista o racismo, como dito, também existem diversas ações, movimentos e formas de combatê-lo tanto em nível teórico como em nível empírico, que são as formas de resistência, com a pretensão de trazer uma valorização das culturas africanas e sua relevância para as bases da formação do mundo moderno. Nesse caminho, iremos destacar dois movimentos, qual seja, a Negritude e os estudos póscoloniais, cujos fundamentos farão parte da nossa análise.

Césaire (2010, p.110), ideólogo e um dos maiores defensores do conceito de Negritude, a define como "uma forma de revolta, em princípio contra o sistema mundial da cultura" ou a um "reducionismo europeu, tal qual ele se constituiu durante os últimos séculos e que se caracteriza por um certo número de preconceitos, de pressupostos que resultaram em uma hierarquia muito rígida". Quer dizer, trata-se da "busca de nossa identidade, afirmação do nosso direito à diferença, aviso dado a todos do reconhecimento desse direito e do respeito à nossa personalidade coletiva" (CÉSAIRE, p. 113).

No mesmo sentido estão os estudos pós-coloniais, mas como um movimento de subversão e combate a vários tipos de discriminação e não apenas ao racismo. Costa (2006) explica que os intelectuais fundadores desse movimento são, sobretudo, imigrantes que saíram de países pobres para a Europa ocidental e América do Norte e que a crítica literária foi uma das áreas primeiras de difusão da perspectiva pós-colonial, principalmente na Inglaterra e EUA em 1980. Essa assertiva é confirmada por Souza (1987) quando aponta que:

Ignorar a dimensão cultural das manifestações artísticas, seu vínculo com a realidade que formam e integram a Literatura, a transformaria em texto desprovido de significação contextual e, consequentemente, restrito a uma ilusória autonomia. E é por reconhecer a fragilidade do discurso crítico literário, pautado exclusivamente em critérios a ele inerentes, que a Teoria da Literatura 
tem dirigido seu olhar para outros ramos do saber, no desejo de melhor conhecer seu objeto (SOUZA, 1987, p. 110).

Assim, a crítica da abordagem colonial recai sobre a produção do conhecimento científico que privilegia os modelos sociais e culturalmente estabelecidos (o que se definiu como cultura nos países europeus), reproduzindo a lógica da relação colonial. As experiências de minorias sociais continuam sendo comparadas a partir das suas semelhanças e diferenças com o que se determinou no centro (COSTA, 2006).

Citando Homi Bhabha, Costa (2006) acredita que a multiplicação das diferenças, entendidas como processos de hibridização, possibilitam a subversão dos discursos totalizantes. A difusão de situações híbridas que fazem parte dos imigrantes e minorias tem sentido positivo, visto que criam possiblidades de articulação de novas diferenças, novos sentidos, introduzindo incerteza, ambiguidade e dúvida naquilo que aparentava ser puro e ordenado. Daí a relevância dos estudos pós-coloniais, pois vão além das pesquisas particulares como os estudos de minorias nacionais, relações étnicas, racismo. O estudo sobre os sujeitos descentrados leva a uma teorização inovadora da relação entre diferença, sujeito e política.

Dentre os intelectuais pós-coloniais que estudam o sujeito, conforme Costa (2006), nomes como Stuart Hall e Paul Gilroy, constroem um marco analítico que nos permite estudar a relação entre sujeito e discurso e identificar o espaço de criatividade do sujeito. Costa (2006, p. 131) se refere a essa teoria como uma contribuição "ímpar e, seguramente, ajuda as ciências sociais a, finalmente, reencontrar seu vigor criativo".

De forma semelhante, o semiótico argentino Mignolo (2008, p. 288) fala da necessidade de uma desobediência epistêmica para que não continuemos presos aos conceitos modernos eurocentrados, fixados em categorias de conceitos gregos e latinos e "nas experiências de subjetividades formadas dessas bases, tanto teológicas quanto seculares", visto que os grupos considerados inferiores tiverem seu agenciamento epistêmico negado.

A opção descolonial implica, necessariamente, em uma desobediência teórica, a qual se desliga dos conceitos genuínos ocidentais de acumulação de conhecimento. Não quer dizer, contudo, que devemos abandonar ou ignorar o já foi institucionalizado, mas sim, significa, entre outras coisas, "aprender a desaprender" já que nossas mentes foram programadas pela concepção imperial, colonial. Ou seja, alimenta um pensamento de um mundo no qual muitos mundos podem coexistir (MIGNOLO, 2008). 
Henrique Cunha Júnior ${ }^{4}$, também reforça e esclarece muitas questões a respeito desta temática. Denominando o pan-africanismo como uma forma de desobediência epistêmica, ressalta que se trata de um movimento contra o eurocentrismo que busca autonomia no pensamento africano. Afirma que não é necessário recorrer às bases europeias quando possuímos o continente africano com conhecimentos milenares que foram a base da modernidade. "Elementos da modernidade digital, já estavam incluídos na forma de pensar e agir africanas há mais de três mil anos, os cálculos de números binários e algoritmos são feitos como se faz no computador, mas de forma manual" (informação verbal).

Cunha Júnior, trata o racismo como um conjunto de dominações e exemplifica o racismo institucional como a falta de representatividade de autores africanos nos acervos das bibliotecas. Diz também que existe uma variedade de plantas, vegetais e costumes originários da África que não é conhecida no Brasil. "A quantidade de coisas de tradição africana que o brasileiro desconhece é enorme. Infelizmente o Brasil não trata a tradição africana como ela merece, não dá a devida dimensão merecida a população negra, com o devido respeito e reconhecimento, vê-se apenas como pessoas ignorantes" reforçou o palestrante. E finaliza: "Não conseguimos tratar com a devida adequação a temática africana, ela ficou como um apêndice dos direitos humanos" (informação verbal).

Nota-se, portanto, a urgente e constante necessidade de debater essa temática bem como formar os sujeitos para uma educação ampla que promova a reflexão sobre a importância que cada cultura tem para o desenvolvimento da sociedade e do respeito e valorização de todas as manifestações culturais. Compreendemos que a educação e a literatura fazem parte dessa formação como instrumentos fundamentais para promoção da empatia e da sensibilização com o outro. Por isso, escolhemos para análise a obra "O mundo no black power de Tayó" como um livro que trata de tal valorização e reflexão.

\section{TAYÓ: UMA MENINA E SEU ORGULHO AFRICANO}

"Sobre a cabeça, a parte do corpo de que ela mais gosta, ostenta seu enorme cabelo crespo, sempre com um penteado chamado black power" (OLIVEIRA, 2013, p. 17).

\footnotetext{
${ }^{4}$ Palestra "Bairros negros: identidade da população negra e educação" proferida no Congresso Nacional de Educação, em João Pessoa, PB, em 15 de novembro de 2017.
}

Revista da ABPN • v. 12, n. $31 \cdot \operatorname{dez} 2019$ - fev 2020, p. 470-491 
No caminho do cenário atual para a valorização das questões sobre direitos humanos, especificamente sobre as culturas africanas, a arte e cultura brasileira não ficaram alheias. Nesse sentido, o mercado editorial brasileiro vem investindo em obras que trazem a África e a temática afro-brasileira como tema central, e os (as) leitores (as) estão podendo se deliciar com obras de grande teor reflexivo. Vargas $(2012$, p.1) diz que "a literatura infantil viu-se tomada de assalto por autores e obras em quantidade e qualidade, de modo que hoje temos setores de mercado voltados para esse recorte temático que, entre outros objetivos, deseja valorizar nossa diversidade étnica e recuperar nossas raízes".

Sobre essa era de riqueza no que diz respeito à presença da multiculturalidade na literatura, compreendemos que os livros para crianças representam um recurso importante, uma vez que eles podem fazer o leitor e a leitora mergulharem, por meio da leitura, nos mais diversos mundos. Com efeito, para Lajolo (1982), a linguagem literária tem a peculiaridade de promover um espaço de interação subjetiva entre as instâncias que permeiam a leitura que se opõe radicalmente ao imediato, ao previsível e aos padrões já instaurados no mundo. Da mesma forma ela não transfere nada, mas cria e dá margem para o provisório da criação. Como coloca Hunt (2010):

Do ponto de vista histórico, os livros para crianças são uma contribuição valiosa à história social, literária e bibliográfica; do ponto de vista contemporâneo, são vitais para a alfabetização e para a cultura, além de estarem no auge da vanguarda da relação palavra e imagem nas narrativas, em lugar da palavra simplesmente escrita (HUNT, 2010, p. 43).

Porém, nem sempre foi assim. Até o final do século XX, os negros, negras e indígenas foram representados na literatura de forma folclorizada e mítica, excluídos da realidade social e quando apareciam na literatura infantil eram estereotipados de modo jocoso, humilhante e inferiorizado. Foi necessário então conhecer e reconhecer como se dá a literatura africana em suas peculiaridades, para assim valorizar a imagem dos negros e das negras bem como de seus descendentes na literatura brasileira, não só no que respeita à sua relevância histórica, mas como forma de construção identitária (AMORIM, 2014).

Essa perspectiva histórica da análise literária é importante para o trabalho na atualidade, uma vez que por meio dos livros literários, os cenários culturais, éticos e estéticos são colocados em cheque. Sobre isso, Silveira e Kaercher (2013) pontuam: 
[...] se durante o século XIX e várias décadas do século XX, temas como desigualdade social, preconceitos em relação aos diferentes problemas familiares, separação de pais, alcoolismo, apenas para citar alguns dentre outros possíveis, estavam ausentes da literatura para crianças, nas últimas décadas do século XX e início do século XXI, tal literatura tem se aberto para abrigar tais tematizações (KAERCHER, 2013, p. 1192).

Um exemplo disso é o livro que escolhemos comentar: "O mundo no black power de Tayó". A utilização da literatura (romances, poesias, músicas) para promover a educação para a diversidade é citada por Moreira (1999, p.88) como um instrumento que contribui para "facilitar a compreensão de que a diversidade é uma construção social, desenvolver o respeito pelo 'outro', bem como ajudar a vencer resistências”.

Em "O mundo no black power de Tayó", conhecemos um pouco da história de uma menina de seis anos, que faz jus ao significado de seu nome, pois ela é muito alegre. Tayó, personagem principal do livro, é uma menina de descendência africana cujo nome vem do iorubá e significa alegria. Seus traços físicos característicos da população negra são muito valorizados e bem aceitos por Tayó, principalmente seu cabelo que é a parte do corpo que ela mais ama, sendo motivo de alegria e orgulho. Ela usa seu penteado no estilo black power, feito por sua mãe, ostentando-o sempre com adornos diferentes.

A autora, Kiusam de Oliveira (Figura 1) é paulista, nascida em Santo André (São Paulo). É uma multiartista, arte-educadora, bailarina, coreógrafa, professora de danças afro-brasileiras, contadora de histórias, pedagoga com habilitações em Orientação Educacional, Administração Escolar e Deficiência Intelectual. Doutora em Educação e Mestra em Psicologia pela Universidade de São Paulo, é ainda especialista nas temáticas das relações étnico-raciais, gênero, corporeidade e candomblé de ketu, além de ativista do movimento negro há quase 30 anos (OLIVEIRA, 2013).

Sobre o tema, ministra cursos, palestras, oficinas e workshops em congressos e universidades em todo o país. É criadora e diretora do programa de rádio "Povinho de Ketu: as africanidades brasileiras no ar”, transmitido pelas rádios públicas nacionais. É bailarina e coreógrafa no show Tecnomacumba, de Rita Ribeiro. Orientadora Espiritual (Iyalorixá) através do jogo de búzios e numerologia africana, tendo, portanto, conhecimento empírico da abordagem pela qual transita e apoia a sua literatura.

Antes de "O mundo no black power de Tayó", a autora publicou "Omo-Obá: histórias de princesas” em 2009, recomendado pela Fundação Nacional do Livro Infantil 
e Juvenil (FNLIJ) em 2010 e selecionado para o PNBE em 2011. Desde o lançamento, "O mundo no black power de Tayó" gerou repercussões no país, sendo ganhador do prêmio PROAC/2012- Cultura Negra e selecionado para o Acervo Básico da FNLIJ/2014, na categoria Criança.

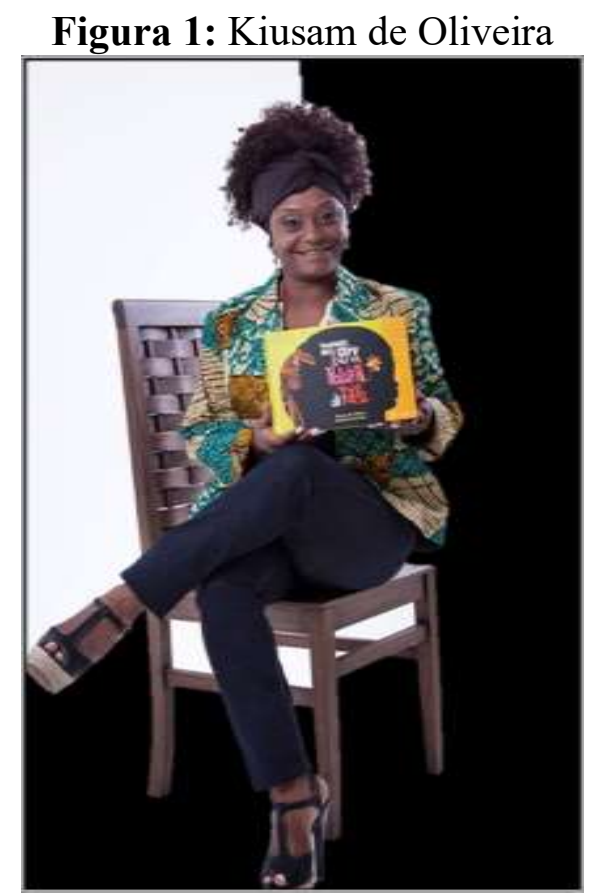

Fonte: Facebook/Kiusam de Oliveira, 2013

No livro de Kiusam de Oliveira (Figura 2) encontramos a história de uma menina que se orgulha de sua cultura negra e que enxerga em seu black power, além de um elemento estético, um traço cultural e étnico-racial. O black power de Tayó é enorme e ela carrega toda sua imaginação ali dentro, como se carregasse o mundo. Tayó se destaca entre as crianças porque valoriza seu cabelo e através dele se coloca enquanto ser no mundo. O seu corpo fala e transcende o universo de identidade, pois vai além do corpo, das questões físicas, é constituinte da sua personalidade, identidade e caráter.

Figura 2: Capa do livro "O mundo no Black Power de Tayó" 


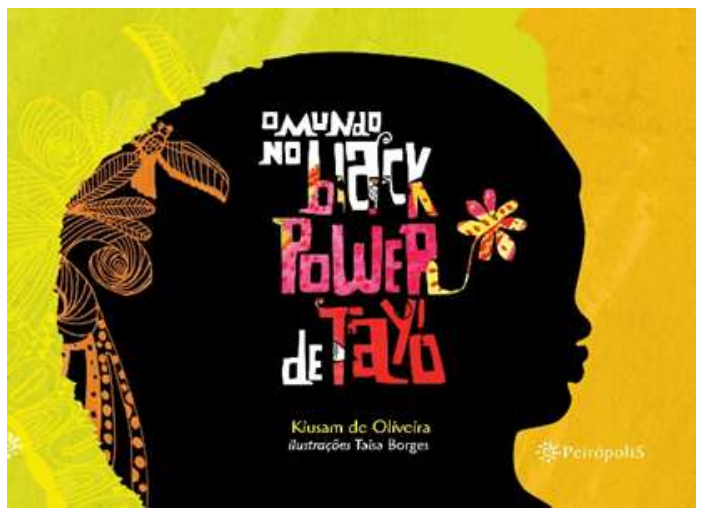

Fonte: Editora Peirópolis $<\underline{\text { http: } / / w w w . e d i t o r a p e i r o p o l i s . c o m . b r / ~}>$

O livro tem trechos poéticos sobre a forma como Tayó e seu corpo se relacionam com o mundo, destacando-se a valorização dos traços físicos, como se vê nos trechos das epígrafes deste artigo e nas seguintes passagens: "Seu nariz parece mais uma larga e valiosa pepita de ouro [...]" ou "Grossos e escuros como o orobô, seus lábios só se movimentam para dizer palavras de amor" (OLIVEIRA, 2013, p. 12, 14).

Dessa forma, o black power, assim como as outras tantas características físicas, se configuram como marcas que identificam um grupo de pessoas que possuem cabelo crespo, da mesma forma que existem diversos tipos de cortes de cabelos em outras culturas como moicanos, oriundos dos povos indígenas. Ambos procuram representar a resistência e identidade do seu povo, pois conforme diz Laraia (2009) o que causa as diferenças entre culturas é a história cultural de cada grupo, aliados à faculdade do homem de aprendizagem e sua dinamicidade, por isso a diversidade de cabelos existentes nas distintas culturas. Faustino (2013) numa espécie de posfácio do livro infantil em análise, esclarece que:

Não é por acaso que os cabelos black power têm o formato circular do universo. A circularidade é a base fundamental das culturas de matriz africana. Deixar os cabelos crescerem livres, soltos, redondos, harmônicos em todos os sentidos, foi a forma encontrada, na distante década de 1960, pela juventude afro-americana, e depois por homens e mulheres afros do mundo todo, de marcar sua identidade e o orgulho de sua origem africana (FAUSTINO, 2013, p. 41).

Assim, além da questão física, os aspectos relacionados a cultura se fazem perceber na obra. Quando diz que o penteado faz o maior sucesso "porque Tayó costuma escolher os enfeites mais divertidos" (OLIVEIRA, 2013, p. 18), a autora nos remete às regiões e comunidades em que o cabelo é símbolo de resistência. Trançá-los pode significar, por exemplo, preparação para as grandes festas ou eventos importantes,

Revista da ABPN • v. 12, n. $31 \cdot \operatorname{dez} 2019$ - fev 2020, p. 470-491 
ao passo que em outros lugares, grandes rainhas e princesas raspam seus cabelos para acomodar as joias e coroas feitas de sementes. Desse modo, subtende-se que na obra em questão o cabelo é tomado como objetos de ostentação, porque Tayó tem algo único em sua sala de aula e ela, como ninguém, sabe valorizar isso. Sobre a riqueza cultural, Amorim (2008) diz que:

Cultura é memória, transmissão e recepção, movência e invariâncias [...]. Na voz e no corpo atualiza-se a tradição cosida com as fibras do lembrar e do esquecer, do ontem e do agora, da mobilidade, das circunstâncias da cultura. O fio da tradição conduz o homem pelos labirintos das infinitas possibilidades do fazer cultural, e justo nas diferenças dessas encruzilhadas, nos reconhecemos (AMORIM, 2008, p. 58)

O fio da tradição colocado por Oliveira (2013) se desdobra em sentidos diversos, mas aqui ele se constitui como algo inerente à condição de existir no mundo com esse ou aquele cabelo. Mais do que existir, o black power de Tayó lhe confere lugar de destaque, uma vez que a valorização étnica e a construção de uma identidade se pautam pela sua história.

Conforme Césaire (2010, p. 112) identidade é aquilo que é fundamental, "aquilo sobre o qual todo o resto se constrói ou pode se construir: o núcleo duro e irredutível; o que dá a um homem [ou a uma mulher], a uma cultura, a uma civilização sua forma própria, seu estilo e sua irredutível singularidade".

Por isso, no livro, a identidade de Tayó é marcada pela valorização a ancestralidade, a admiração da beleza da sua raça e sua autoestima elevada. Assim, a narradora diz: “quando amanhece, Tayó acorda com uma alegria capaz de contagiar toda a cidade onde mora. Seu corpo se ilumina. Olha para sua mãe, linda como ela, e tem a certeza de que nasceu mesmo de uma rainha" (OLIVEIRA, 2013, p.35).

É, pois, graças a essa identidade que Tayó fortalece seu orgulho e confiança para superar os desafios do preconceito. A narrativa relata uma passagem em que os (as) colegas de escola chamam seu cabelo de "ruim":

Bem-humorada, quando seus colegas de classe dizem que seu cabelo é ruim, ela responde:

- Meu cabelo é muito bom, porque é fofo, lindo e cheiroso. Vocês estão com dor de cotovelo, porque não podem carregar o mundo nos cabelos como eu posso (OLIVEIRA, 2013, p. 27). 
Candau (2003, p. 18) conceitua que o preconceito é uma atitude e a discriminação é uma prática social, ou seja, um tratamento diferenciado. De forma mais detalhada, a discriminação pode ser entendida como um processo de controle social que "serve para manter a distância social entre determinados grupos, através de um conjunto de práticas, mais ou menos institucionalizadas, que favorecem a atribuição arbitrária de traços de inferioridade por motivos [...] independentes do comportamento real das pessoas que são objetos da discriminação".

Assim, diante das atitudes preconceituosas, Tayó recorre à sua ancestralidade, como o escudo e fonte de sabedoria e orgulho. Tanto pela resistência contra a escravidão e opressão como por sua cultura forte e rica. Nesse sentido, ao voltar para casa e pensar em toda falta de gentileza de seus (suas) colegas, Tayó projeta em seu penteado:

[...] mesmo sem se dar conta disso, todas as memórias do sequestro dos africanos e das africanas, sua vinda à força para o Brasil nos navios negreiros, os grilhões e correntes que aprisionavam seus corpos. Tudo isso está bem guardadinho bem lá no fundo da sua alma [...]

[...] todos os sons e cores alegres das tradições que negros e negras conseguiram criar e preservar, como as danças, os jogos, as religiões de matriz africana, as brincadeiras, os cantos, as contações de histórias e todos os saberes, demostrando que nem correntes nem grilhões conseguiram aprisionar a alma potente dos seus antepassados (OLIVEIRA, 2013, p. 28, 31)

A acusação feita ao cabelo de Tayó, advém de uma concepção anglo-saxã que preza e define como padrão de beleza a cor branca e o cabelo liso em detrimento de outras possibilidades estéticas e culturais de afirmação da identidade (GOMES, 2003). Ou seja, trata-se da ideia colonialista da imposição cultural (COSTA, 2006; LARAIA, 2009; MIGNOLO, 2008). Mas Tayó de forma "desobedientemente epistêmica", partindo de uma concepção contra hegemônica, responde com muita confiança sobre as qualidades do seu cabelo, enfatizando o orgulho por ela sentido. Desse modo, a formação identitária de Tayó lhe é tão segura que lhe permite ser quem ela, de fato, se propõe a ser.

Em se tratando do ambiente escolar, é importante destacar a função que a escola possui nesse contexto, qual seja, o de promover o respeito e valorização da diversidade cultural. Candau (2003, p. 24) reconhece que "a instituição escolar representa um microuniverso social que se caracteriza pela diversidade social e cultural e por, muitas vezes, reproduzir padrões de conduta que permeiam as relações fora da escola”.

Revista da ABPN • v. 12, n. $31 \cdot \operatorname{dez} 2019$ - fev 2020, p. 470-491 
Conforme Coelho (2000) escola é o lugar privilegiado para o encontro entre o leitor e o livro, no qual devem ser "lançadas as bases para a formação do indivíduo", já que para ela a escola, ao contrário da concepção e da sua tradição reprodutora, disciplinadora e rígida, deve ser um espaço de libertação e orientação proporcionando ao indivíduo refletir sobre si mesmo e sobre a cultura do mundo.

Por isso, é necessário que a escola problematize e desnaturalize essas ações preconceituosas, a fim de não se tornar uma reprodutora da discriminação. Ou como disse García Canclini (2005) é necessário adotar metodologias híbridas para dar conta da variabilidade das identificações, já que os sujeitos não pertencem mais a apenas uma cultura. No texto abaixo, observamos como a poeta recifense, Odailta Alves trata poeticamente este tema:

\section{RACISMO INSTITUCIONAL}

A escola é a artéria Que alimenta bravamente $\mathrm{O}$ racismo institucional

Lá, desde cedo Quanto mais escura é a pele

Maior é a chicotada E tudo

Tudo é tão normal A incomodada que se muda

Enquanto ecoa

O preconceito racial:

Cabelo duro, macaca, bicuda

Carvão, escrava, Saci

E a negra "prejudica o senso"

"Diminui o Ideb"

Pois foi mais uma a desistir.

Para essa velha doença

Não bastam leis no papel

Nem discurso verbal

Há séculos ela corrói

Mata, segrega

A solução?

Algo assim

Bem surreal:

Ampolas da 10.639/03

Talvez direto na veia

Ela atinja a mente

E destrua para sempre

O genocídio racial 
(ALVES, 2017, p. 12-13)

Desse modo, Tayó carrega em seu penteado mais que características estéticas. Ela carrega em seu black power a própria história, o choro das separações, o silenciamento das práticas religiosas, o cerceamento da alimentação e da liberdade, pois toda a diáspora pode ser rememorada nesse universo simbolizado pelo penteado de Tayó. Sua descendência se revela na percepção que ela tem do universo da população negra, e assim, os costumes são valorizados por conhecer sua própria história.

A autora projeta na protagonista o que deve ser considerado como importante para o fortalecimento da identidade: "Tayó é o que todas as outras meninas como elas são: princesas que vivem a carregar, sobre seus penteados, suas coroas reais, mesmo que não as vejam, quando estão acordadas" (OLIVEIRA, 2013, p. 39). Esse aspecto é bastante caro à educação na perspectiva da multiculturalidade, uma vez que entra em cena o processo educacional como uma maneira de formar melhor os sujeitos, reestabelecendo algumas ordens que pareciam estar perdidas nesse universo que mistura os aspectos culturais ao que, de fato, cada povo pode produzir.

Quando se percebe a riqueza desses aspectos, sobretudo por meio da literatura, não há motivos para que as crianças não se identifiquem com as personagens, com suas lutas e histórias e, assim, tornar mais reflexivo o debate sobre o preconceito.

Como um elemento fundamental para que o trabalho nas escolas tenha sucesso é necessário que haja uma ampla formação de professores para sensibilizá-los e preparálos para tratar desta temática em sala de aula. Dessa forma, Moreira (1999) elucida que o uso de autobiografias, narrativas pessoais e o contato com diferentes experiências pode torná-los mais sensíveis para refletir e desenvolver metodologias de ensino que auxiliem no combate ao racismo.

Por fim, como forma de destacar outro elemento relevante na construção e apreciação de uma obra infanto-juvenil, qual seja a ilustração, no livro em questão, esse recurso se configura como uma contribuição relevante para a compreensão da narrativa e das culturas africanas. Na obra, a ilustração é um aspecto que merece atenção, pois o texto e a imagem foram unidos para ampliar a construção de sentidos em torno da temática identidade, utilizando-se de recursos gráficos e cores típicas das culturas africanas (Figura 3). Neste sentido, Machado et. al. (2012, p. 164) afirmam que, alguns dos elementos presentes nessas obras são: 
[...] ricos em cortes, traços fortes, que quase nos fazem ouvir batuques e danças. Em desenhos e figuras inspiradas nas culturas africanas, representações de adornos de cabeça, colares, bordados e pedrarias acompanham textos de recontos e de suas tradições.

Figura 3: Ilustração do livro "O mundo no black power de Tayó"

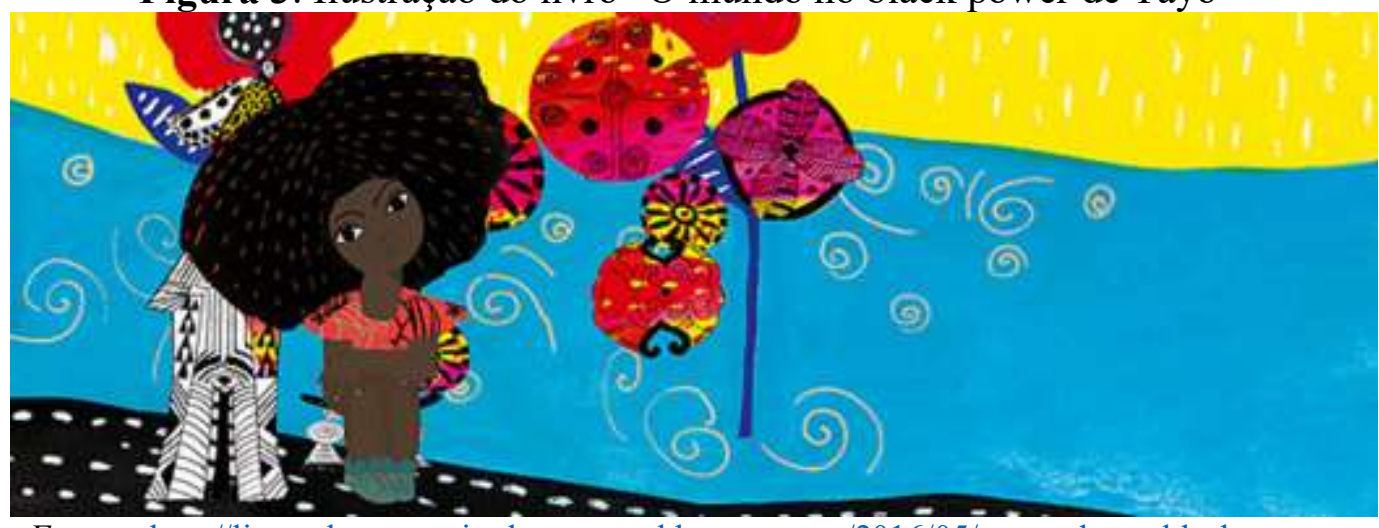

Fonte: $<$ http://livrosabertosaquitodoscontam.blogspot.com/2016/05/0-mundo-no-black-powerde-tayo-um-livro.html> 2016.

Como forma a dar destaque a outras obras que dialogam com a escolhida, assim como nessa obra, muitas outras abordam a questão da valorização capilar, sempre na perspectiva do enaltecimento desse traço como componente identitário da etnia negra, conforme se vê nas capas abaixo (Figura 4).

Figura 4: Exemplos de livros que dialogam com "O mundo no black power de Tayó"

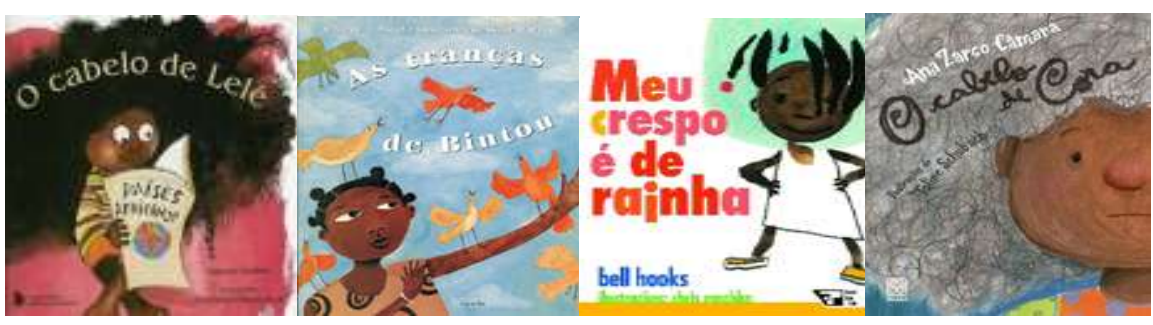

Todas essas obras têm como intenção levar a criança a refletir sobre a importância da valorização identitária, do reconhecimento de aspectos de sua história, por meio da relação que os aspectos étnico-raciais fazem eclodir. Não deixa de ser uma conquista e um avanço a publicação dessas obras que contribuem para a formação dos sujeitos.

Sendo assim, a obra estudada deixa a contribuição, não só no campo da literatura como principalmente, no contexto histórico, cultural, religioso e social, na qual 
percebemos o quão importante são os processos de aprendizagem e que não existe uma cultura melhor que outra, pois elas se completam, num processo contínuo de troca e de aprendizagem.

\section{CONCLUSÃO}

"O black power de Tayó é enorme, do tamanho da sua imaginação. Ela ama tanto os bichos, a natureza, os alimentos, as pessoas e os planetas que, por vezes, projeta todo esse universo em seu penteado" (OLIVEIRA, 2013, p. 24).

A construção do pensamento e das relações entre os seres humanos se pauta naquilo que é vivido, naquilo que é falado, naquilo que é estabelecido nessa convivência. As construções de determinado grupo social sempre carregarão suas marcas porque elas são parte de cada um e cada uma que ali se encontra e se relaciona. Ou seja, somos sujeitos culturais, ou melhor, multiculturais. Para a escola, o desafio é estabelecer as conexões entre o que é cultural e o que é curricular, como também lidar com essa diversidade inerente à raça humana. Assim, a literatura se constitui um importante instrumento para o trato das questões que circundam o desenvolvimento da sociedade.

A literatura se constitui elemento chave para que a sociedade conheça a sua história, perceba suas conquistas e, especialmente, para fazer com que os sujeitos se construam e reconstruam a sua história. Em "O mundo no black power de Tayó", a literatura empresta à linguagem escrita a ideia da construção de uma identidade forte, capaz de se estabelecer uma nova forma de pensar. Com a história de Tayó a identidade negra é valorizada, tanto no que diz respeito ao reconhecimento das especificidades físicas como das heranças culturais. O direito a conhecer a sua história é relevante para que o sujeito se constitua perante seus pares e, consequentemente, consiga viver em sociedade. Portanto, quando é oferecido referenciais literários de personagens com os quais os sujeitos se identificam, existe a possibilidade de projeção no outro, dos sucessos e superações.

A obra de Kiusam de Oliveira oportuniza variadas formas de tratar o tema, instigando diálogos e reflexões, considerando não só sua delicadeza, mas também a urgência de seu tratamento. Devido as distintas formas de discriminação que existem e a preocupação com o combate a essas práticas, o mercado editorial vem trazendo à tona 
obras semelhantes que abordam não só a temática do racismo ou da consciência negra mas também discussões referentes as questões de gênero, etnia, casses sociais entre outros. Tais temas são essenciais para discussão dos direitos humanos e para uma verdadeira formação integral.

A propósito da Lei 10.639/2003 (BRASIL, 2003), muitos/as educadores/as desenvolvem em suas salas de aula projetos de trabalho com uma variada gama de atividades que levam os (as) estudantes, assim como Tayó, reconhecer as riquezas culturais de seus antepassados. Além disso, promovem a autonomia desses (as) alunos e alunas a conviverem com as mais diversas manifestações de violência às quais são expostas.

Portanto, mediar situações onde essa discriminação possa ser problematizada é um dos grandes desafios para os educadores e educadoras atuais, uma vez que esses processos estão em todos os lugares. Um elemento fundamental para que o trabalho nas escolas tenha sucesso é a formação de professores (as), para que possam dar conta das questões que se desdobram em torno das práticas discriminatórias, para que possam ser sensibilizados (as) e preparados (as) para tratar desta temática em sala de aula.

Assim, há de se convir que a escola, as famílias e a sociedade em geral devem atuar no desvelamento do mito da democracia racial e no trato às questões relativas ao racismo, num movimento de reconhecimento das diferenças como algo fundamental para as ações e convivência humanas, dessa forma afirmando a pluralidade cultural e mitigando os estereótipos raciais (CANDAU, 2003).

Uma vez que se trata a diversidade por meio dos espaços de mediação de conflitos, através dos textos literários se promove a possibilidade de dar voz aos que se identificam com as questões tratadas nos textos. As práticas educativas de combate à discriminação são, portanto, um importante recurso que se dispõe para que as crianças possam sentir-se como Tayó, com sua identidade fortalecida e pronta para enfrentar com leveza e atitude as mais diversas manifestações de indiferença e atos discriminatórios.

\section{REFERÊNCIAS}

ALVES, Odailta. Clamor Negro. Recife: A autora, 2017.

AMORIM, Eliã Siméia Martins dos Santos. A literatura infanto-juvenil e a construção identitária negra. Revista da Associação Brasileira de Pesquisadores/as Negros/as (ABPN),

Revista da ABPN • v. 12, n. $31 \cdot \operatorname{dez} 2019$ - fev 2020, p. 470-491 
[S.1.], v. 6, n. 13, p. 329-350, jun. 2014. Disponível em: http://abpnrevista.org.br/revista/index.php/revistaabpn1/article/view/165. Acesso em: 07 fev. 2019.

AMORIM, Maria Alice. No visgo do improviso ou A peleja virtual entre cibercultura e tradição: comunicação e mídia digital nas poéticas da oralidade. São Paulo: EDUC, 2008.

BRASIL. Lei 10.639, de 9 jan. 2003. Altera a Lei 9.394, de 20 dez. 1996, que estabelece as diretrizes e bases da educação nacional, para incluir no currículo oficial da Rede de Ensino a obrigatoriedade da temática "História e Cultura AfroBrasileira". Diário Oficial da União.

Brasília, DF, 9 jan. 2003.

. Ministério da Educação/Secad. Diretrizes curriculares nacionais para a educação das relações étnico-raciais e para o ensino de história e cultura afro-brasileira e africana na educação básica. 2004.

CANDAU, Vera Maria Ferrão. Sociedade, discriminação e educação. In: (coord.). Somos tod@s iguais? Escola, discriminação e educação em direitos humanos. Rio de Janeiro: DP\&A, 2003.

CÉSAIRE, Aimé. Negritude, etnicidade e culturas afro nas Américas. In: Discurso sobre a negritude. Belo Horizonte: Nandyala, 2010.

COELHO, Nelly Novaes. Literatura Infantil: teoria: análise: didática. São Paulo: Moderna, 2000 .

COSTA, Sergio. Desprovincializando a Sociologia: a contribuição pós-colonial. São Paulo, Revista Brasileira de Ciências Sociais (RBCS), v. 21, n. 60, fev. 2006. Disponível em: http://www.scielo.br/pdf/rbcsoc/v21n60/29764.pdf. Acesso em: 20 maio 2015.

FAUSTINO, Oswaldo. Ser bela e ser feliz. In: OLIVEIRA, Kiusam de. O mundo no black power de Tayó. São Paulo: Peirópolis, 2013.

GARCÍA CANCLINI, Néstor. Quem fala e em qual lugar: sujeitos simulados e pósconstrutivismo. In:_. Diferentes, Desiguais e Desconectados: mapas da interculturalidade. Rio de Janeiro: Ed. UFRJ, 2005. Cap. 7. p.183-208.

GEERTZ, Clifford. A interpretação das culturas. Rio de Janeiro: LTC, 1989.

GOMES, Nilma Lino. Cultura Negra e educação. Rev. Bras. Educ. 2003, n.23, pp.75-85.

HUNT, Peter. Crítica, teoria e literatura infantil. São Paulo: Cosacnaify, 2010.

LAJOLO, Marisa. O que é literatura. São Paulo: Brasiliense, 1982.

LARAIA, Roque de Barros. Cultura: um conceito antropológico. Rio de Janeiro: Zahar, 2009.

MACHADO, Emilia et. al Da África e sobre a África: textos de lá e de cá. São Paulo: Cortez: 2012.

MIGNOLO, Walter D. Desobediência Epistêmica: a opção descolonial e o significado de identidade em política". Cadernos de Letras da UFF - Dossiê: Literatura, língua e identidade, n. 34, p. 287-324, 2008. Disponível em:http://www.uff.br/cadernosdeletrasuff/34/artigo18.pdf. Acesso em: 09 maio 2015. 
MOREIRA, Antônio Flávio Barbosa. Multiculturalismo, currículo e formação de professores. In: Currículo: políticas e práticas. Campinas, SP: Papirus, 1999.

OLIVEIRA, Kiusam de. O mundo no black power de Tayó. São Paulo: Peirópolis, 2013.

SILVEIRA, Rosa Maria Hessel; KAERCHER, Gládis E. da Silva. Dois Papais, duas Mamães: novas famílias na literatura infantil. Educação \& Realidade, Porto Alegre, v. 38, n. 4, p. 11911206, out./dez. 2013. Disponível em: http://www.scielo.br/pdf/edreal/v38n4/10.pdf. Acesso em: 25 maio 2017.

SOUZA, Eneida Maria de. Literatura e antropologia: o conceito de universal. Cadernos de Linguística e Teoria da Literatura, [S1], n. 18-20, p. 109-115, dez. 2016. Disponível em http://www.periodicos.letras.ufmg.br/index.php/cltl/article/view/10136/9052. Acesso 25 jan. 2018.

VARGAS, Suzana. Da África e sobre a África: de modas a modismos. In: MACHADO, Emilia et. al. Da África e sobre a África: textos de lá e de cá. São Paulo: Cortez: 2012.

\section{AGRADECIMENTOS}

Agradecemos as valiosas contribuições das (os) pareceristas ah doc e ao apoio da professora Eliene Amorim de Almeida.

Recebido 30/11/2019

Aprovado em: $30 / 01 / 2020$ 